\title{
HISTÓRIA, MEMÓRIA E MORTE DO IMPERADOR ROMANO GORDIANO III (III-V D.C.)
}

History, Memory and Death of the Roman Emperor Gordian III (III-V AD)

\section{RESUMO}

No presente artigo, nos dedicaremos à contextualização e análise acerca de um busto masculino, em mármore, descrito como de "um imperador vestido com um corselete", encontrado na Vila da Caserna, em Antioquia de Orontes, e identificado como Gordiano III que governou o império romano entre os anos 238 e 244 d. C., uma vez que foram lançadas dúvidas se este seria uma representação de Gordiano III ou de Treboniano Galo. Julgamos, como sugeriu, antes, Dericksen M. Brinkerhoff, que o busto se trata, de fato, de Gordiano III pela relação estreita da vida desse imperador com a história da cidade de Antioquia. E ainda propomos, como hipótese, que o mencionado busto imperial junto com toda a coleção da qual é pertinente seja compreendida dentro de um contexto religioso e, portanto, como portadores de significados religiosos.

Palavras-chave: Memória. Morte. Gordiano III. Estatuária. Antioquia de Orontes.

\author{
Érica Cristhyane \\ Morais da \\ SILVA \\ (D)ecmsilva@gmail.com \\ Universidade Federal \\ do Espírito Santo, \\ Vitória, ES, Brasil
}

\begin{abstract}
In this article, our aim is to contextualize and to make an analysis about a male bust, in marble, described as "an emperor dressed in a corset", found in The Barracks House, in AntiochontheOrontes, and it is, conventionally identified as Gordian III who ruled the Roman empire between the years 238 and 244 AD, but doubts were raised as to whether this would be a representation of Gordian III or Trebonianus Gallus. We believe, as Dericksen $M$. Brinkerhoff suggested, that the bust is in fact Gordian III because of the close relationship between the life of this emperor and the history of the city of Antioch. And we also propose, as a hypothesis, that the aforementioned imperial bust, together with the entire collection of which it is pertinent, be understood in a religious context therefore as having religious meanings.
\end{abstract}

Keywords: Memory. Death. Gordian III. Late Antique Statuary. AntiochontheOrontes. 


\section{A Vila da Caserna e a descoberta de uma coleção de estátuas em Antioquia}

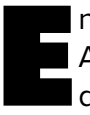
ntre os anos de 1932 e 1939, foram realizadas campanhas de escavação em Antioquia e suas vizinhanças sob a responsabilidade de um comitê de escavações que congregava representantes do Museu Nacional da França, o Louvre, o Baltimore Museum of Art e o Worcester Art Museum, a Universidade de Princeton e, nas campanhas de escavações de 1936, se junta a essa delegação, representantes do Fogg Art Museum da Universidade de Harvard e sua filiada a Dumbarton Oaks. Dentre as descobertas resultado dessas campanhas, se encontrou enterradas, uma coleção de estátuas. ${ }^{1}$ O lugar de enterramento da coleção de estátuas é o espaço de "um cômodo de uma vila datada entre finais do século IV e inícios do século V d.C. localizada nas adjacências do muro da cidade" de Antioquia (STILLWELL, 1938, p. 3). ${ }^{2}$ As vilas se constituem em uma estrutura importante, parte da cidade romana antiga. Na região do Levante, as vilas estão próximas aos núcleos urbanos como é o caso das vilas de Antioquia de Orontes locadas nos seus arredores ou no subúrbio de Dafne (GRAF, 2001, p. 228). E o estudo desse tipo de residências extramuros de Antioquia apresenta alguns problemas. Primeiro é digno de nota que as escavações em Antioquia tinham objetivos e direcionamentos, a priore, por exemplo, os registros mais detalhados e os estudos e reflexões mais completos são sobre os mosaicos encontrados nas residências, sem mencionar, um outro importante problema, as pilhagens frequentes (STILLWELL, 1961, p. 47; LEVI, 1947). Na obra Antioch mosaic paviments, de Doro Levi (1947), podemos ter acesso aos resultados das escavações referentes às vilas e aos mosaicos encontrados. Nesta obra, em particular, são apresentadas plantas baixas das vilas com localização dos mosaicos nos ambientes da casa e uma análise substancial e significativa de vários dos mosaicos descobertos. Todavia, no setor $25 \mathrm{H}$, que nos interessa, na Vila da Caserna (LEVI, 1947, p. 316), onde foram encontradas a coleção de estátuas e entre as quais incluise o busto que chamamos a atenção, e que é objeto de nossa reflexão aqui, não há um tratamento maior sobre o tema da estatuária encontrada. Há apenas informações superficiais, a apresentação apenas da planta baixa da estrutura residencial da vila com a localização dos mosaicos (Figura 1).

Doro Levi (1947, p. 316) somente nos informa que houve "uma descoberta casual de um depósito de esculturas antigas no recinto da caserna, em novembro de 1934" que veio impulsionar uma escavação no local trazendo a luz uma residência com vários fragmentos de mosaicos, mas que, segundo o autor, "nenhuma investigação adicional foi realizada". Nesse sentido, o estudo dessa coleção de estátuas tem limitações e alguns obstáculos no desenvolvimento de uma reflexão e interpretações mais amplas. Não obstante, a própria coleção em si pode ser alvo de inferências de modo que possamos contribuir ao debate em direção de uma compreensão mais contextualizada de seu significado e argumentar em favor de uma interpretação religiosa agregada à coleção, no geral, e ao busto imperial, no particular.

As estátuas descobertas na Vila da Caserna eram tanto imagens imperiais quanto estátuas de deuses, heróis e personagens mitológicas. As estátuas eram as seguintes:

As estátuas de deuses, heróis e personagens mitológicas: II.1. Um fragmento de uma estátua masculina sem cabeça no qual se preserva os ombros, parte do braço 


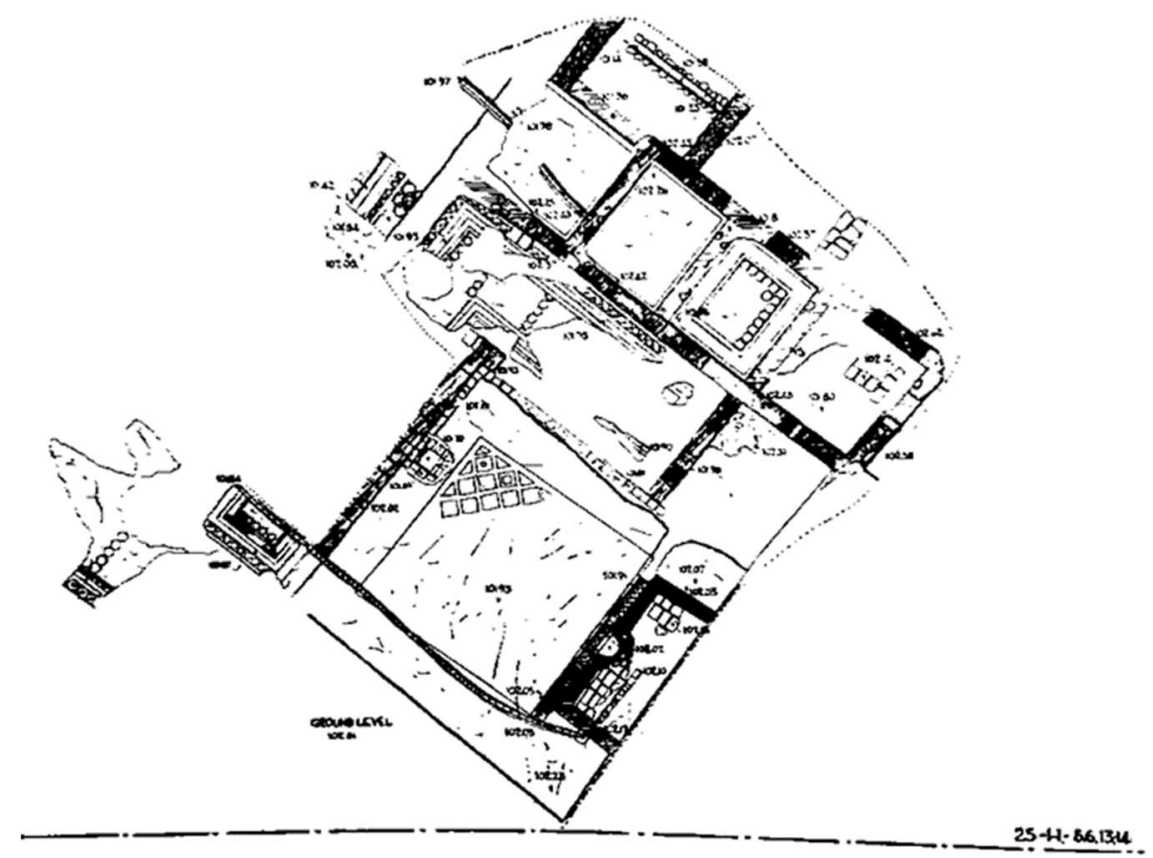

Figura 1 - Plano da Vila da Caserna

(Setor 25 - H, Antioquia)

Fonte: LEVI, 1947, p. 316.

esquerdo e da perna também esquerda até a altura do joelho. Há uma particularidade nesta estátua, a presença de uma mão presa nas costas e com a palma a mostra supondose, conforme Brinkerhoff (1970, p. 30), que seja a representação de Meléagro, herói grego, em cópia helenística; II.2. Uma outra estátua masculina e sem cabeça e identificada pelos arqueólogos da escavação como sendo um sátiro, foi classificada por Brinkerhoff (1970, p. 30-32) como sendo uma cópia romana do deus Dionísio, que remontaria à época severiana; II.3. Uma cabeça "de um homem com elmo", possivelmente, considerado como uma réplica do deus da guerra, Ares, produzido em meados do século III d.C. como uma cópia de um estilo Ático original (BRINKERHOFF, 1970, p. 32-33); II.4. Uma "cabeça feminina", podendo ser datada da época de Constantino e caracteristicamente uma réplica do deus Apolo se considerado em conjunto com um outro fragmento de estátua que somente a parte dos membros inferiores foram preservado, da altura do joelho aos pés, constituído de uma veste drapeada (BRINKERHOFF, 1970, p. 35-36); II.5. Uma cabeça de "um velho sátiro barbudo", datável do governo de Galieno (253-268). Representa uma cópia de um tipo helenístico do território da Ásia Menor (BRINKERHOFF, 1970, p. 37-38); II.6. Entre outras divindades, ainda é possível identificar duas estátuas de Afrodite de tipo 
helenístico. Como argumenta Brinkerhoff (1970, p. 38), uma das Afrodites apresenta uma cerâmica aos seus pés, de modo que funcionasse como uma fonte de água, uma prática comum na Antiguidade Tardia; II.7. A outra Afrodite é nomeada por Brinkerhoff (1970, p. 38), de "Afrodite atando suas sandálias", e segundo os Archaeological Archives, da Universidade de Princeton $(25 H)$, classificada como um "torso feminino desnudo (de Afrodite), em mármore"; II.8. Por fim, "um velho Sileno adormecido" (BRINKERHOFF, 1970, p. 40).

As imagens imperiais: I.1. Um busto masculino, em mármore, que se supôs ser de um filósofo, mas que foi reconhecido como uma representação do imperador Pertinax que governou entre os anos 192 e 193; I.2. Outro busto masculino, em mármore, denominado como de "um imperador vestido com um corselete" e identificado como Gordiano III que governou entre os anos 238 e 244 (Figura 2); I.3. Uma cabeça porfiróide masculina que remonta à época tetrárquica e que foi identificada como sendo do imperador Constâncio I Cloro, cujos anos de governo foram entre 293 à 306 (LSA 523).
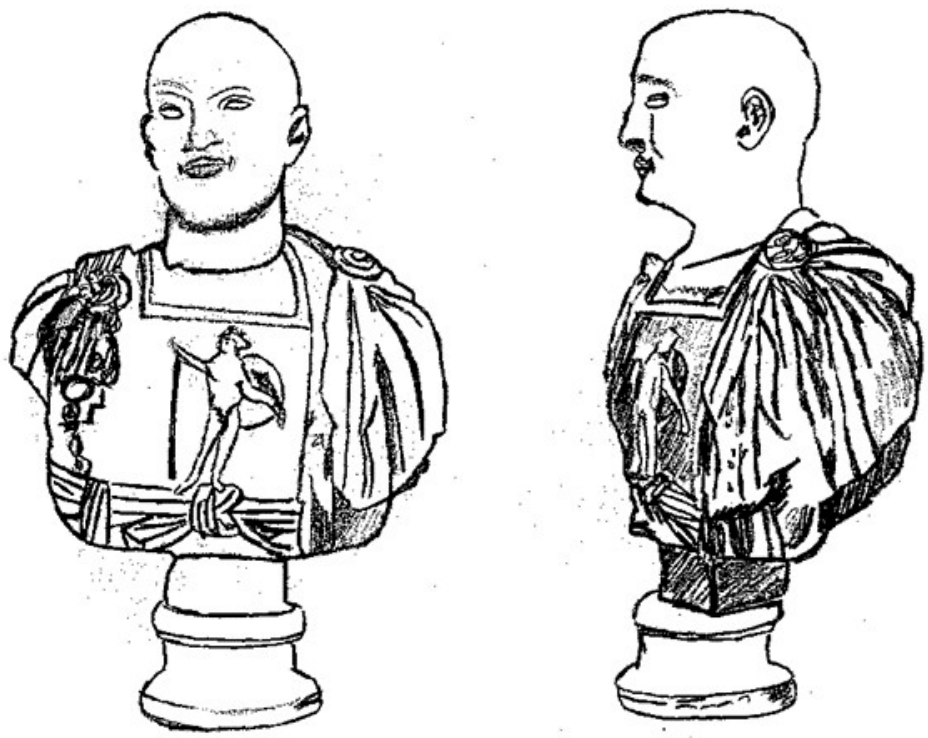

Figura 2 - Reconstituição do busto de Antioquia (Gordiano III)

Fonte: Desenhado pela própria autora do artigo com base na fotografia existente das campanhas de escavação. As fotografias estão disponível em http://vrc.princeton.edu/ archives/items/show/14019 e http://vrc.princeton.edu/archives/items/show/14020. Uma imagem mais detalhada do busto de Antioquia pode ser vista em Last Statues of Antiquity Database, registro n. LSA 254. Disponível em http://laststatues.classics.ox.ac.uk/database/ detail.php?record=LSA-254. 


\section{As imagens imperiais da Vila da Caserna: Treboniano Galo ou Gordiano III?}

As imagens imperiais encontradas na Vila da Caserna foram identificadas como sendo dos imperadores Pertinax, Constâncio Cloro e Gordiano III (ou, em argumentação alternativa, em lugar de Gordiano III seria Treboniano Galo) (POLLITTI, 1972, p. 203; INAN, J.; ALFÖLDI-ROSENBAUM, 1979, p. 127-130, n. 76, Plates 67.2 e 68; Figura 2). A identificação de Pertinax e Constâncio Cloro às representações estatuárias encontradas na coleção da Vila da Caserna não parecem ser ponto de debate ou dissensão entre os estudiosos, mas a referente a Gordiano III dúvidas Ihe são lançadas. A sugestão é de que o busto imperial em questão seja de Treboniano Galo uma vez que apresenta muito mais semelhanças com as várias representações deste imperador, que governou o império entre 251 e 253 d.C. Desse modo, o argumento de identificação é muito mais vinculado aos elementos de tipologia estatuária do que às fortes indicações históricas e religiosas que fazem da opção por Gordiano III uma identificação mais condizente com todo o contexto da coleção salvaguardada, da vila antioquena e da história de Antioquia.

Brinkerhoff faz uma defesa em favor de que o busto masculino com corselete seja identificado como Gordiano III. Todavia, Brinkerhorff analisa a vestimenta e todos os aspectos simbólicos representados na couraça do busto até as características técnicas de produção de estátuas em oficinas antioquenas e embora citando os aspectos históricos que vincula Gordiano III à história antioquena pouco os desenvolve, afirmando apenas que Gordiano teria salvo Antioquia de Sapor I. Este autor segue a sugestão indicada pelos responsáveis pelas campanhas de escavações à Antioquia que primeiro argumentaram de que o busto se tratasse de Gordiano III uma vez que este tinha sido resguardado na história de Antioquia e para os antioquianos como aquele imperador que salvou a cidade e os habitantes do domínio persa de Sapor I (CAMPBELL, 1936, p. 9). E novamente, pouco se desenvolve em direção de fortalecer essa identificação mediante a compreensão histórica e contextualização de Gordiano III junto à história da cidade de Antioquia. Assim, apesar deste marco histórico e memória vinculada ao imperador Gordiano III seja, em nossa opinião, um importante aspectos a ser melhor desenvolvido, junto com a contextualização da relação com as outras peças da coleção, as metodologias de comparação visual, tipologia estatuária e estilo ainda permanecem como esteio de identificação e definição da representação. E, para Brinkerhoff, o peso dos argumentos técnicos e tipológicos do busto em si pesaram mais na identificação e argumentação do autor para afirmar Gordiano III como o representado no busto com corselete. Em complementação, buscaremos aqui, portanto, desenvolver mais os elementos históricos e contextuais vinculados a escolha por Gordiano III em detrimento à indicação de Treboniano Galo uma vez que, cremos nós, sejam marcadores tão importantes quanto os aspectos tipológicos e de estilos de estatuária. Assim, comecemos primeiro afirmando que Treboniano Galo se considerado como sendo o imperador representado no busto, contextualmente, este seria uma escolha um pouco fora do lugar e sem sentido. Inferimos que Treboniano Galo não parece ter uma atuação imperial que pudesse nos indicar uma aceitação pela perspectiva antioquena. Segundo Harold Mattingly (1946, p. 36), "alguns reinados são curtos, possuem poucos registros na história e existem pouco conteúdo" sob os 
quais podemos inferir algo. Mattingly ainda finaliza afirmando, "estes estão suscetíveis a permanecerem obscuros".

Das poucas informações que temos disponível do governo de Treboniano Galo, sabemos que este imperador não era muito popular. Inicia seu governo sob a suspeita de conspiração contra seu antecessor junto com Godos e os Cítios. (STERN, 2013, p. 68-46). Mas Treboniano empreendeu esforços para aumentar sua popularidade com o interesse na sucessão dinástica, a ascensão e afirmação de seu filho, Volusiano. Segundo Gaius Stern, Ele tentou aliviar a peste que, embora de sucesso limitado, foi apreciado. Ele imitou o exemplo de seus predecessores, nomeadamente Caracala, ao se apresentar para as pessoas como um homem forte, um militar seguindo o modelo atlético (ou menos provável de um gladiador), uma estátua grandiosa foi pensada para ser a representação de Treboniano como um imperador em um forte, com pose heróica com musculatura excessiva e um rosto ameaçador, suas representações em moedas seguem na mesma direção. Mas apesar de todos esses esforços, a política, que poderíamos dizer internacional, de Treboniano não apresentava grandes impactos. Ao contrário, os persas superaram armênios e ocuparam a Síria. Se consideramos Treboniano Galo no conjunto das representações imperiais da coleção da Vila da Caserna, ele parece não ter qualquer aderência ao conjunto Pertinax, Constâncio Cloro.

Pertinax não parece ter tido uma conexão muito estreita e contínua com a cidade de Antioquia, contudo, a carreira militar deste se inicia no território da Síria antiga e tornase governador desta província entre os anos de 180 e 182 d.C. (DOWNEY, 1961, p. 236). A imagem deste imperador é, inclusive, positiva sendo visto como um governante prudente e, como governador da Síria, Pertinax é concebido como honesto, gentil e cuja disciplina militar era admirável (Scriptores Historia Augustae, III, 1; Herodianus, Historiae de Imperio post Marcum, II, 4, 1; MECKLER, 2019, p. 1). Pertinax foi também divinizado e, possivelmente, por solicitação de Septímio Severo sendo, portanto, parte do panteão religioso romano (Herodianus, Historiae de Imperio post Marcum, II, 10, 19; RMR 117). Desse modo, não nos parece estranho a presença de um busto de Pertinax em uma vila antioquena. Constâncio Cloro é pagão e politeísta. E, embora, geralmente, se relaciona este imperador com divindades solares, em particular, associado com Apolo, Constâncio Cloro foi um pagão tradicional que cultuava o panteão romano tradicional com ênfase em Júpiter e Hércules o que não descarta a associação solar a posteriori dado a extensa promoção desse divindade após a morte de Constâncio (SMITH, 2000; SMITH, 1997a, p. 187-208). A presença desta imagem evoca a tradição tetrárquica de um mundo politeísta e de marco na história de culto imperial. Pertinax e Constâncio Cloro possuem uma relação significativa que os vincula à cidade de Antioquia, romanos tradicionais. Pertinax, como mencionamos anteriormente, possui estreitos laços com a província da Síria. Constâncio Cloro por sua filiação religiosa, pagã e politeísta, torna este imperador muito próximo às tradições religiosas antioquenas. Já Treboniano Galo, por sua vez, embora seja uma personagem sobre a qual possamos ter poucas evidências documentais, seria improvável, caso este imperador fosse figura ilustre na história antioquena, alvo de honra e exaltação, não ter alguma evidência disso. Ao contrário, Treboniano e sua política em relação ao oriente mostraramse pouco dignas de permanecerem lembradas de maneiras laudatórias ou mesmo suas 
imagens sendo alvo de culto imperial, ou resguardadas em ambiente doméstico em contexto antioqueno. Ademais, Treboniano, até onde podemos saber, não parece ter sido divinizado, ao contrário dos outros imperadores, Pertinax e Constâncio Cloro. Do ponto de vista militar e da relação com a parte oriental do império, Pertinax e Constâncio Cloro são personagens, provavelmente, mais aderentes à memória dos antioquenos. ${ }^{3}$

Antioquia é uma cidade quartelgeneral com tropas e acampamentos militares instalados em seu território (PETIT, 1955, p. 177-179). Como território estratégico, Antioquia sempre se caracterizou como um espaço de disputas entre o império romano e o império persa e os imperadores romanos a valorizavam como uma cidade importante dentro do Império. À época do governo de Treboniano Galo (251253), Antioquia recai sob domínio persa, sob o governo de Sapor I. E ao contrário de Gordiano III, Treboniano não produz ofensivas contra os avanços de Sapor I ou se quer fortaleceu as defesas da fronteira oriental contra as incursões persas e a anexação da Síria e de Antioquia ao império persa (MOORE, 2019, p. 1). Assim, as insatisfações dos antioquenos contra o governo de Treboniano somase a uma série de descontentamentos locais contra o governo central e suas respostas às crises que abatiam diretamente a população das cidades do oriente, em especial, a cidade de Antioquia (DOWNEY, 1961, p. 253-255). Além disso, um outro grande componente complicador deste contexto é a deflagração de uma pandemia que duraria pelo menos quinze anos e que ficou conhecida como a Praga de Cipriano, "uma pandemia esquecida" e nomeada em favor do bispo de Cartago que oferece um testemunho vívido sobre os acontecimentos (DOWNEY, 1961, p. 254; HARPER, 2015, p. 224). Dado esse panorama, Gordiano III como a representação imperial indicativa do busto com corselete é uma opção mais harmônica e que completa o quadro tripartite imperial: Pertinax, Gordiano III e Constâncio Cloro. Gordiano III tem laços mais estreitos com a cidade de Antioquia e seus habitantes. Este imperador é resguardado na história da cidade como o salvador dos antioquenos que estava sob ameaça de domínio persa uma vez que Sapor I havia se apossado de grande parte do território da próspera cidade de Antioquia de Orontes (TOWNSEND, 1934, p. 127). Na primavera de 242, a Síria foi invadida e Antioquia sitiada, mas Gordiano III junto com tropas romanas conseguiram fazer com que os persas recuassem na conquista (DOWNEY, 1961, p. 253; TOWNSEND, 1934, p. 127). Além disso, em nossa opinião, os argumentos "estéticos" e "artísticos" utilizados seja para confirmar ou refutar a verossimilhança ou não do busto com as imagens de Gordiano III e de Treboniano Galo não são suficientes para explicar e/ ou definir, determinar, a relação entre o artefato arqueológico encontrado na Vila da Caserna e os imperadores seja ele, o primeiro ou este último. A argumentação de J. J. Pollitti (1972, p. 203), ${ }^{4}$ como segue abaixo, é razoável:

Com base em análises formais e comparações seletas, Brinkerhoff identifica uma das imagens como Pertinax, a outra, com maior hesitação, como sendo Gordiano III, e a terceira, uma cabeça profíria no estilo icônico dos tetrarcas de Veneza, como sendo de Constâncio Cloro. Os argumentos para a primeira e a última dessas identificações são convincentes, 
mas os argumentos para a imagem de Gordiano, embora não completamente sem mérito, são, pelo menos, abertas a alguma dúvida. As representações de Gordiano no Terme e em Sofia que são aceitos como imagens do Gordiano maduro parecem mais jovem e causa uma impressão mais suave e gentil do que a representação do busto de Antioquia. É certo que existem algumas semelhanças estruturais, mas se considerarmos todos os fatores o busto de Antioquia e as representações típicas de Terme-Sofia simplesmente não parecem representarem a mesma pessoa. Em seu Prefácio, Brinkerhoff toma nota e rejeita a sugestão de Suheyla Keskil que o busto de Antioquia representa Treboniano Galo. Infelizmente, essa proposta chamou atenção dele somente quando seu próprio trabalho estava em processo de publicação e ele não pôde lidar com a proposta detalhadamente. O busto de Antioquia tem a mesma forma e o mesmo desconforto na boca que o retrato de bronze no Museu Metropolitano, que muitos o identificam como Treboniano. Brinkerhoff sugere, muito razoavelmente, que seria mais natural para antioquenos preservar uma representação de Gordiano, o suposto salvador de Antioquia, do que de Treboniano, e a proposta do autor, de que o busto de Antioquia foi produzida a partir de reparos na imagem de uma representação de Maximino Trácio pode explicar suas diferenças em relação as outras representações de Gordiano. Mas, à parte das hipóteses e do contexto histórico, o busto de Antioquia parece, pelo menos nas fotografias, muito mais como Treboniano do que com Gordiano.

No entanto, pensar "á parte das hipóteses e do contexto histórico", como propõe Pollitti, e extrair da equação a importante contextualização histórica e a harmonia do conjunto estatuário imperial em contexto doméstico - uma vila romana na Antiguidade Tardia - e regional - a história de Antioquia e a relação de seus habitantes com os imperadores - é no mínimo desconsiderar todo o próprio alicerce [a grade de sentidos] mediante o qual os residentes poderiam dar significado a materialidade que os cercavam. E a verossimilhança das representações nem sempre foi um aspecto imprescindível. É compreensível que os aspectos técnicos artísticos e estéticos das estatuárias são importantes, mas não são determinantes últimos ou definitivos. Jeremy Tanner (2000, p. 18) já destacava que: "Trabalhos recentes na história da arte antiga têm procurado ir além das interpretações formalistas das obras de arte, para uma preocupação em entender as imagens antigas em termos de uma visão mais ampla" que incluam os "contextos cultural, político e histórico". R. R. R. Smith (1997b, p. 171) demonstrou, com o estudo de uma representação de Licínio I, o quanto as representações imperiais têm "valores históricos e políticos" na medida em que difundem "ideias políticas" e "agendas políticas".

O contexto histórico, político e cultural pode também renomear os representados e pré-datar a estatuária a despeito dos estilos e da tipificação em processos de inferência artística os quais são necessários, mas não são exclusivamente determinantes, vide, por exemplo, a análise de R. R. R. Smith (1997b, p. 170-202) sobre "um rosto de formas arredondadas incomum da antiguidade tardia" a qual considera ser a 
imagem de Licínio I com base em "valores históricos". Segundo Smith (1997b, p. 171), as "imagens têm valor histórico - não em termos de novos fatos históricos, mas em termos de representação de ideias políticas. Estes tipos de imagens permitiram aos contemporâneos visualizar diferentes agendas morais, culturais e políticas". Neste sentido, o conjunto das considerações estéticas, artísticas, estilísticas bem como contextuais (histórico, político e cultural) contribuem, conjuntamente, para a análise de uma imagem e da importância e lugar que ocupa em determinado espaço, evento, ambiente. Os argumentos artísticos e de estilos, somado a breve consideração contextual e histórica, de Brinkerhoff acerca do busto de Antioquia podem ser, como Pollitt destacou no excerto anteriormente citado, "abertos a questionamentos", não obstante, se compararmos a história de Treboniano Galo à história de Gordiano III e a relação destes com a cidade de Antioquia como descrevemos anteriormente, não parece plausível optar por reconhecer Treboniano em detrimento de Gordiano III na representação do busto de Antioquia, na Vila da Caserna. E para adicionar a esses argumentos, nos parece ainda mais significativo compreendermos as narrativas sobre a morte de Gordiano III e como este imperador se eterniza na memória mediante relatos posteriores. Não somente a morte, mas também a divinização de Gordiano III, evidenciado por Amiano Marcelino (Res Gestae, XXIII, 79), torna esse imperador como a melhor opção que explique e identifique a representação imperial do busto antioqueno. Brinkerhoff propõe uma representação adequada apesar dos argumentos frágeis porque centrada fundamentalmente em argumentos estéticos e em breves argumentos históricos. O contexto histórico e políticosocial, pouco explorados pelo autor, ao contrário do que se julga, fornecem, certamente, argumentos mais robustos e densos.

\section{A morte de imperadores romanos: $\mathrm{O}$ caso de Gordiano III}

As mortes de imperadores romanos foram, geralmente, violentas e súbitas (MEIJER, 2004). Conforme argumenta François Pieter Retief e Louise Cilliers (2006, p. 89, 98-99), desde a nomeação de Augusto como primeiro imperador, em 27 d.C. até a deposição de Rômulo Augusto, em 476, o Império Romano foi governado por setenta e sete imperadores e destes, cinquenta e nove imperadores são governantes entre os anos de 193 e 476 d.C., entre os quais quinze morreram de causas naturais ou doenças, cinco casos foram suicídio, trinta e dois casos, execução e assassinatos e sete casos motivos diversos como, por exemplo, morte em batalhas, morte na prisão e morte por afogamento (Tabela 1). 
Tabela 1 - Causa das mortes de Imperadores (193-476 d.C.)

\begin{tabular}{|c|c|c|}
\hline \multicolumn{3}{|c|}{ Morte por causas naturais e doenças - 15 casos $(25,4 \%)$} \\
\hline Causa incerta & 7 & $\begin{array}{l}\text { Constantino; Constâncio Cloro (?); Teodósio; Honório; } \\
\text { Severo III; Glicério; Rômulo Augusto }\end{array}$ \\
\hline Doença epidêmica & 1 & Cláudio II \\
\hline Palidez extrema & 1 & Constâncio Cloro \\
\hline $\begin{array}{l}\text { Ulceração de abdômen e } \\
\text { genitais }\end{array}$ & 1 & Galério \\
\hline Derrame & 1 & Valentiniano I \\
\hline $\begin{array}{l}\text { Envenenamento } \\
\text { (alimentar? Cogumenlos) }\end{array}$ & 1 & Joviano \\
\hline Gota crônica & 1 & Septímio Severo \\
\hline Raio & 1 & Caro \\
\hline Edema & 1 & Olíbrio \\
\hline \multicolumn{3}{|l|}{ Suicídio - 5 casos $(6,8 \%)$} \\
\hline Enforcamento & 2 & Gordiano I, Maximiniano \\
\hline $\begin{array}{l}\text { Exsangüinação (corte } \\
\text { dos pulsos) }\end{array}$ & 1 & Quintílio \\
\hline Inanição & 1 & Diocleciano \\
\hline Envenenamento & 1 & Maximiano Daia \\
\hline \multicolumn{3}{|c|}{ Execução e assassinato - 32 casos (55,9\%) } \\
\hline $\begin{array}{l}\text { Mortos por espadas ou } \\
\text { adagas }\end{array}$ & 29 & $\begin{array}{l}\text { Pertinax; Dídio Juliano; Caracala; Geta; Macrino; } \\
\text { Heliogábalo; Severo Alexandre; Maximino; Pupieno; } \\
\text { Baldino; Gordiano III; Trebonio; Emílio; Galieno; Aureliano; } \\
\text { Tácito; Floriano; Probo; Carino; Numeriano; Severo II; João, } \\
\text { o Usurpador; Valentiniano III; Maioriano; Antêmio; Nepo }\end{array}$ \\
\hline Enforcado & 1 & Licínio \\
\hline Estrangulado & 1 & Ávito \\
\hline Apedrejado & 1 & Petrônio Máximo \\
\hline \multicolumn{3}{|r|}{ Outras causas - 7 casos $(11,9 \%)$} \\
\hline No campo de batalha & 5 & Gordiano II; Filipe, o Arábe; Décio; Constantino II; Juliano \\
\hline Na prisão & 1 & Valeriano \\
\hline Afogamento & 1 & Maxêncio \\
\hline
\end{tabular}

Fonte: RETIEF; CILLIERS, 2006, p. 98-99, tradução nossa.

Gordiano III integra o grupo de imperadores que morreram assassinados. A definição das circunstâncias de sua morte, no entanto, é problemática e pouco evidente. Duas 
tradições podem ser relatadas. A primeira que a morte de Gordiano III teria sido causada pelo seu prefeito do pretório e sucessor ao reino, Filipe, o Árabe, mediante a ação da própria tropa imperial (Ammianus Marcelinus, Res Gestae, XXIII, 5, 78 e 17; Scriptores Historia Augusta, Gord. XXIXXXX; Aurelius Victor, Caes. XXVII, 78; Epit. De Caes. 27, 13; Eutr. IX, 2, 23; Festus, XXII; Jer., Chron.; Oros. VII, 19, 5; Zos. I, 18-19). A segunda tradição fundamentada na documentação denominada de Res Gestae Divi Saporis, uma inscrição de Sapor I descoberta em 1939, que desafia a aceitação geral da primeira tradição. Na inscrição (RGDS, 610), a versão sassânida da morte de Gordiano III é significativa:

(6) Assim que nos estabelecemos em nosso reinado sobre as províncias, o César Gordiano (7) [reuniu] (a), de todo o Império dos Romanos, um exército (pertencente às) províncias góticas e alemãs (b); e, invadindo a Assíria, ele tomou a ofensiva contra a nação dos arianos e contra nós. E nas (ou nas) fronteiras (8) da Assíria (c), no Misiche, ocorreu uma grande batalha (d), e o César Gordiano foi morto (?) (E), e nós destruímos o exército dos romanos; e os romanos (9) proclamaram Filipe César, e César Filipe chegou à composição (/) e, para resgatar a vida de seus amigos, ele nos deu 500.000 denários; e ele se tornou nosso tributário. (10) E nós chamamos por este motivo Misiche Peros-Sabour (= Sapor é vitorioso).

O relato na inscrição é de que Gordiano III foi morto em campo de Batalha em campanha contra o rei Sapor I. O exército romano foi destruído e Filipe, o Árabe, o sucede no trono e Roma se torna tributária da Persia de Sapor I. Classicistas e orientalistas debatem há décadas sobre uma e outra tradição buscando compreender e definir as circunstâncias da morte de Gordiano III. ${ }^{6}$ Claro que a documentação epigráfica sassânida está eivada de interesse na exaltação da figura de Sapor I sob o imperador romano, o que reforça mais ainda a importância dada à morte de Gordiano III e a existência de uma diversa tradição narrativa. A memória sobre a morte do imperador Gordiano III tornase matéria de uma luta de representações (CHARTIER, 1990, p. 17). Filipe, o Árabe, pela força representativa do governo de Gordiano III, não poderia, portanto, recorrer ao dispositivo a que outros imperadores recorreram, a damantio memoriae do imperador assassinado. Para fortalecer ainda mais a versão encontrada na Res Gestae Divi Saporis e afastar as suspeitas sobre si de conspiração contra um imperador popular, como evidência Mark Johnson (1995, p. 141), mediante as fontes clássicas, destaca que Filipe, o Árabe: ${ }^{7}$

[...] escreveu ao Senado relatando que Gordiano morrera de doença e solicitando que as honras divinas Ihe sejam concedidas. Um monumento, referido como "tumulus" ou "sepulcro" nas fontes, é erguido no local do assassinato, com vista para o rio Eufrates em Zaitha, não muito longe Circesium (Buseire moderno, Síria) na estrada para Dura Europos. 
O sepulcro de Gordiano III apresenta ainda uma originalidade. Como nos recorda Johnson, "durante os dois primeiros séculos do Império, a tradição que se seguia à morte de um imperador, era a realização de um funeral e seus restos mortais eram depositados em um dos mausoléus imperiais em Roma”. Mais uma vez Gordiano III está mais associado aos territórios do oriente romano do que à tradicional península itálica embora nascido e pertencente à uma das famílias tradicionais em Roma. ${ }^{8}$ Mais significativo ainda é o relato de Amiano Marcelino sobre as campanhas de Juliano contra a Persia onde ele relata que Juliano não apenas visitou o túmulo de Gordiano III mas ainda realizou rituais de sacrifício ao divus Gordiano III (JOHNSON, 1995, p. 142). Gordiano III foi divinizado em algum momento e reconhecido como divus mediante cerimônia de apoteose (McDONALD, 1981, p. 507). Assim, as imagens imperiais que poderiam receber culto seriam, certamente, o de imperadores mortos e, possivelmente o de imperadores vivos pela ambiguidade que se infere quando estas estão em companhia ou próximas às estátuas divinas (FISHWICK, 1990, p. 121-130).

O culto imperial é um aspecto tão importante à cultura romana que resistiu até mesmo à um decreto de Teodósio II, em 425, em que ele declarava "um culto em excesso à dignidade humana deve ser reservada apenas à suprema divindade". Para concluir, voltemos ao busto imperial antioqueno da coleção da Vila da Caserna. Nesse contexto, a escolha pela representação de Gordiano III em um busto no contexto desta coleção, e no interior do espaço doméstico desta vila e dada a proximidade deste imperador à história da cidade de Antioquia e com o oriente, nos parece muito mais plausível e inteligível. Assim, a coleção de estátuas da Vila da Caserna ainda merece uma atenção especial em seu significado e sentido o qual argumentamos possui, para além de mobiliário, um sentido religioso no contexto doméstico. O culto privado de imperadores em espaços domésticos não é algo extraordinário e muito menos impossível de se conceber como prática corriqueira na sociedade romana. As vilas romanas eram também espaços sagrados, espaços de rituais compartilhados. E, embora, evidências arqueológicas sobre o culto imperial em espaços domésticos sejam escassas, não significa pensar que a prática era inexistente.

\section{O culto imperial doméstico: Gordiano III em contexto religioso na Vila da Caserna}

O culto imperial tem sido concebido, em geral, como um fenômeno, exclusivo e predominantemente, da esfera pública (GRADEL, 2002, p. 198; YANDEK, 2013, p. 1). ${ }^{9}$ Não obstante, a presença de estatuária, imagens e representações imperiais ocorria em contextos domésticos como depreendemos a partir de evidências literárias (Ovid, Epistulae Ex Ponto, 2, 8, 1-6, 2, 8, 55-56) e arqueológicas, mosaicos e pinturas parietais em Pompeia e Óstia, inscrições, arquitetura e artefatos encontrados em Éfeso, Delos e Pergamo e, claro, o caso de Antioquia com a presença de três estátuas de imperadores na Vila da Caserna. E apesar dos problemas impostos por essas documentações, nos parece plausível argumentar em prol da existência de uma significativa prática religiosa e de culto à pessoa do imperador em contexto doméstico e privado. ${ }^{10}$ Ittai Gradel (2002, p. 199) sugere que "as honras imperiais em contexto doméstico centravamse 
em cultuar o imperador reinante, assim como ocorreria no culto ao imperador em geral (ou, de fato, no culto ao imperador em qualquer contexto excetuando o culto público em Roma)". Não obstante, Gradel propõe uma análise do culto imperial "como uma prática honorífica (nem exclusivamente religiosa nem exclusivamente política), que expressava o poder absoluto do príncipe em seu povo" traçando, cronologicamente, o surgimento do culto ao imperador, em Roma, e suas mudanças no principado nas esferas doméstica e pública" (LAIRD, 2003, p. 1). Para "além da infinidade de templos públicos, há evidências de um culto privado significativo ao imperador, incluindo ofertas e rituais ao imperador deificado feitos nas casas de cidadãos particulares" (CALLAHAN, 2008, p. 23-24; TAYLOR, 1975, p. 151-152; RATHMAYR, 2006). Para o contexto da Antiguidade Tardia, há continuidade, na porção oriental do império romano, de cultos aos imperadores romanos não somente em rituais públicos, mas também nos rituais domésticos (e privados) e, ambos - tanto o culto público quanto o doméstico e privado - não eram incompatíveis com a emergência do cristianismo que buscou afazer-se ao mores romano (SETTON, 1941).

O culto imperial doméstico e privado por parte das famílias e indivíduos era simples e consistia, principalmente, de queima de incensos frente à imagem do imperador e ofertas de comidas e bebidas em conexão com os deuses domésticos (BURTON, 1912, p. 84-85). Em novembro de 392, ao banir as práticas de sacrifícios (libações de sangue?) mediante lei, Teodósio (CTh. XVI, 10,12) nos fornece preciosas informações sobre os componentes dos rituais religiosos em contexto doméstico:

\begin{abstract}
Nenhuma pessoa, de nenhuma classe ou ordem, quaisquer homens ou aqueles com dignidades, quer ele ocupe uma posição de poder ou findo o exercício de certa honra, quer ele seja uma pessoa de prestígio e status por nascimento, ou provenientes de uma ascendência humilde, com status jurídico e fortuna, deverá sacrificar uma vítima inocente em nome de imagens sem sentido em nenhum lugar, nem em cidade alguma. Ninguém deverá, por meios secretos perversos, venerar seus lares com fogo, seu genius com vinho, seus penates com odores perfumados; ninguém pode acender luzes para eles, colocar incenso diante deles, ou pendurar coroas neles.
\end{abstract}

Esses dados extraídos de estatuto jurídico do Código Teodosiano sobre as práticas religiosas domésticas também podem ser encontrados em cultura material e as evidências provenientes das Casas-Terraço da cidade de Éfeso é um caso ímpar. Desde 2005, com a publicação de resultados das escavações, em Éfeso, sobre as Casas-Terraço, temos estudos significativos e detalhados sobre as unidades residenciais 1, 2, 4, 7 da Casa-Terraço 2 e sobre o culto imperial em espaço doméstico e privado (YANDEK, 2013, p. 105; THÜR, 2005; KRINZINGER, 2010; RATHMAYR, 2020; 2017; 2006; ZIMMERMANN, 2019). As Casas-Terraço são, conforme define Amy C. Yandek (2013, p. 102), uma série de casas de indivíduos da elite construídas na encosta acima do fórum principal de Éfeso romana, e consistem em duas unidades principais de construção, Hanghaus 1 e Hanghaus 2. 
A ínsula, conhecida como Hanghaus 2, é composta por sete unidades residenciais projetadas como casas de pátio peristilo, em três terraços, ricamente decorados com mosaicos, pinturas de parede e esculturas (RATHMAYR, 2006, p. 103). Nesta CasaTerraço, a documentação arqueológica se amplia desde configurações arquiteturais tanto quanto cômodos dedicados ao culto de divindades e exedras com pinturas parietais e estátuas de divindades até achados arqueológicos de pequenos altares e imagens de divindades e objetos religiosos como thymiateria (incensários) e depósitos para ofertas (ZIMMERMANN, 2019, p. 211-219; RATHMAYR, 2006, p. 103123). Em especial, no cômodo SR 29 desta habitação, Elisabeth Rathmayr (2006, p. 123) destaca que:

[...] existem grafites em uma camada de tinta mais antiga chamada salutaris. Podese supor que este seja o cavaleiro de descendência italiana de C. Vibius Salutaris, que era descendente de italianos e era ativo nos tempos de Trajano em Éfeso. A conhecida inscrição Salutaris de Éfeso, que estipula, entre outras coisas, que estatuetas de prata do Imperador Trajano e sua esposa Plotina deveriam ser mantidas na casa dos Salutaris e adoradas em forma de culto, fornece uma indicação clara do culto imperial na esfera doméstica.

Além disso, um friso de mármore, encontrado na SR 18.1 da Casa-Terraço 2, no qual o imperador Trajano é descrito como um general e que pode ter sido um adorno em uma sella curulis, aponta para uma importante conexão com o proprietário dessa unidade residencial e o imperador: este artefato junto com a inscrição e o grafite sugerem, como destaca Rathmayr (2006, p. 124), que os habitantes adoravam as estátuas do imperador e sua esposa. Outro testemunho de culto imperial, nesta Casa-Terraço, é descoberto no cômodo 38, onde foi encontrado uma exedra onde estavam locados bustos, em tamanho real, de Tibério e Lívia e, ademais, a presença de um altar e uma mesa de mármore reforçam a sugestão que a casa imperial era, neste espaço, cultuada (RATHMAYR, 2006, p. 124; 2017, p. 115).

Ao que tudo indica, o culto de imperadores vivos e, posteriormente, mortos também é observável pela continuidade da presença de bustos imperiais na última fase desta Casa-Terraço que foi destruída e não mais utilizada como residência no último quartel do século III d.C. (RATHMAYR, 2006, p. 127-128). Ainda sobre esta Casa-Terraço 2, na unidade residencial 2, cômodo 24, Amy C. Yandek (2013, p. 133) supõe a possível identificação de um busto imperial como sendo de Gordiano I e destaca que a legitimidade do governo de Gordiano III poderia ter sido reforçada pela divinização dos dois Gordianos anteriores. O próprio Gordiano III foi divinizado. Segundo Yandek (2013, p. 133),

se esta é a identificação do busto, seria interessante como uma manifestação doméstica do culto imperial, já que a tendência é de um grande papel público da elite. A localização fora de um peristilo luxuoso sugeriria que a presença do busto do imperador seria não apenas para sua adoração, mas também 
para exibição social, reforçando a identidade e pertencimento do próprio proprietário à uma elite.

De fato, o culto à imperadores romanos "na esfera privada indica uma identificação ou uma conexão dos residentes com o poder dominante" (RATHMAYR, 2017, p. 116), mas, por outro lado, também produz uma relação sagrada que funda um espaço de culto privado e de compartilhamentos religiosos em ambientes domésticos (ZIMMERMANN, 2019, p. 212-229). A presença de um busto imperial com possível identificação como da dinastia Gordiana, em Éfeso, e em contexto religioso, é evidência significativa para nosso estudo de caso em Antioquia. Todavia, à luz dessas evidências abundantes, no caso de Éfeso, cujo dados permitem arguir acerca de culto imperial em contexto doméstico e privado, as estátuas imperiais da Vila da Caserna, em Antioquia, em especial o busto de Gordiano III (Figura 2), nos impõe dois importantes desafios: 1) a dificuldade de inferência às representações de imperadores mortos e divinizados e sua vinculação à um contexto de práticas religiosas domésticas e privadas dado que, 2) as representações foram encontradas enterradas em um dos cômodos de uma vila que, como dissemos antes, só nos restaram a planta baixa - sem vestígios de presença de elementos que caracterizam contexto religioso de rituais - e, por isso, nos impõe alguns entraves interpretativos por ausência de evidências." Mas, apesar desses entraves, o caso dos cultos imperiais domésticos em Éfeso nos fornece algumas soluções possíveis. Conforme Rathmayr (2006, p. 128), enquanto para as unidades residenciais 2 e 7 o culto imperial pode ser comprovado, dois outros bustos imperiais, também pertencentes a Casa-Terraço 2, são mais difíceis de avaliar a esse respeito, mas, a localização permite uma suposição razoável de que pertenciam ao cenário de uma das duas unidades residenciais. Ainda de acordo com a autora, embora o contexto dessa escultura não seja conhecido, o busto pode ter tido uma função religiosacultural devido ao seu pequeno tamanho uma vez que se sabe que pequenos bustos imperiais foram colocados juntos com outras divindades em santuários (RATHMAYR, 2006, p. 128).

O conjunto de bustos encontrados no cômodo 7 da Casa-Terraço 2, um pequeno e um em tamanho real, possivelmente desempenharam a função de culto embora, segundo Rathmayr (2006, p. 130), não se possa afirmar com certeza. Um outro importante aspecto que precisamos destacar é que localizados nesse cômodo, tratamse de representações de imperadores mortos porque presentes em espaço da residência datada à época da última fase residencial, século III d.C. À luz dessas evidências, o caso do busto de Antioquia é passível de ser interpretado como parte de um contexto religioso. Primeiro, porque o busto de Antioquia apresenta dimensões com característica portátil, medindo a cabeça, desde o queixo ao topo, $22 \mathrm{~cm}$, largura de 44 cm, altura de $81 \mathrm{~cm}$ (STILLWELL, 1938, p. 172, n. 134, Plate 5; LENAGHAN, 2020). Embora, este não seja de pequena dimensões - os bustos pequenos do caso de Éfeso são $19 \mathrm{~cm}$ e $23 \mathrm{~cm}$ - só esse critério não é algo que o exclua como parte de um contexto religioso haja vista os bustos de Tibério e Lívia, em tamanhos reais, no cômodo 38 da Casa-Terraço 2. Tanto em Éfeso como em Antioquia, podemos arguir, em nossa opinião, em favor da relação entre dimensão e importância do culto para 
os proprietários. Nesse sentido, considerando a dimensão do busto de Antioquia, Gordiano III, pode ter sido o segundo em importância no conjunto do culto imperial na Vila da Caserna dado que o busto de Pertinax tem $84 \mathrm{~cm}$ e o cabeça de Constâncio Cloro 22 cm (STILLWELL, 1938, p. 172, Plates 5 e 6).

A escolha do lugar onde se localizavam as estátuas tem um significado e é importante se eram, por exemplo, espaços decorados e se o mobiliário pertencia à área com acesso aos outsiders, convidados, clientes, ou estavam restritas à cômodos privativos aos habitantes da casa (RATHMAYR, 2017, p. 109). J. Lenaghan (2020) declara que o busto foi encontrado em cômodo da Vila da Caserna que, provavelmente, poderia ser a cozinha. O espaço da cozinha de uma vila é também lugar bastante significativo uma vez que possam conter utensílios de culto como recipientes para libação, exedras, incensários (thymiateria), como é possível depreendermos do cômodo SR9d, da Casa-Terraço 2, em Éfeso (RATHMAYR, 2006, p. 112). Além desses elementos, para compreendermos o busto imperial de Antioquia como sendo de Gordiano III e, por conseguinte, a associação deste com um contexto religioso, é preciso tratarmos o conjunto de estátuas da Vila da Caserna como uma unidade.

A preferência dos donos da Vila da Caserna por determinados deuses (Apolo, Ares, Afrodite, Dionísio) tem estreita relação tanto com a história local. Antioquia é uma cidade "quartelgeneral" (PETIT, 1955, p. 177-179), de acampamentos militares e lugar do grande templo de Apolo em seu subúrbio, Dafne (SILVA, 2020, p. 215-218), e tendo Dionísio como um deus importante dada a fama antioquena dos grandes festivais e espetáculos teatrais e o teatro, na asty antioquena, era denonimada Teatro de Dionísio (CARVALHO; SILVA, 2020, p. 13-57). O conjunto das estátuas imperiais, Pertinax, Constâncio Cloro e Gordiano III, encontradas na Vila da Caserna, se mostram como um grupo homogêneo em termos de afinidades e semelhanças no que se refere, por exemplo, à história destes imperadores e o vínculo deles entre si bem como a ligação de cada um com a cidade e seus habitantes. Primeiro, todos os três foram reconhecidos divi: Pertinax foi consagrado divus pelo seu sucessor, Septímio Severo (GONÇALVES, 2007, p. 20-35); Constâncio Cloro consagrado divus depois de morto em 25 de julho de 306 (HURLET, 2015, p. 187; JOHNSON, 1992, p. 145; Eutropius, Breviarium, X, 1); o imperador Juliano já conheceu Gordiano III como divus (MAcDONALD, 1981, p. 507). Segundo, todos os três imperadores são lembrados por suas conquistas e/ou reveses no âmbito militar: embora ele não tenha tido tempo de governar apropriadamente, Pertinax ocupou comandos importantes na Síria, no curso de sua carreira militar, antes de se tornar imperador, na Britannia e em Moesia e foi alvo de três conspirações que atentaram contra sua vida (MEIJER, 2004, p. 6668). Apesar de uma carreira militar com feitos significativos, mas com uma relação complexa com a guarda pretoriana, Pertinax é visto como um "líder modesto morto por causa da avareza dos soldados" (MECKLER, 2019; GARZON BLANCO, 1984, p. 204-207); a campanha de Constâncio Cloro da invasão e recuperação da Britannia (EICHHOLZ, 1953); a ofensiva de Gordiano III contra o império persa e o bloqueio ao avanço estrangeiro em direção à Antioquia (DIGNAS; WINTER, 2007, p. 22). 
O simbolismo do torso no busto da estátua de Antioquia referente ao imperador Gordiano III são reveladores (Figura 2), neste sentido. No centro da couraça, podemos perceber "uma figura militar com elmo, nua, portando uma lança, um escudo e uma espada presa por uma alça de ombro, e que olha para uma Nike esculpida na aba do ombro direito" (BRINKERHOFF, 1970, p. 13). Embora, mesmo que o busto apresente características de reuso porque a cabeça foi recolocada no torso, representação de um outro imperador, ${ }^{12}$ esse conjunto de imagens remete à aspectos presentes na representação do imperador à época e do governo de Gordiano III. A deusa Vitória e o guereiro desnudo evoca a imagem do imperadorguerreiro, o uso do paludamentum informam um emperador pronto e armado para a batalha num todo de uma propaganda de sucessos militares (HEBBLEWHITE, 2016, p. 37-43). E, por fim, todos estes imperadores parecem ter tido um bom relacionamento com a elite e a aristocracia, seja à época de seus respectivos governos, seja porque foram assim resguardado na memória para a posteridade, como podemos depreender das imagens laudatórias de "bons imperadores" nos dados biográficos de Pertinax, Gordiano III e Constâncio Cloro descritos em obras importantes da literatura romana. Na História Romana, de Herodiano (II, 4, 1), Pertinax é visto como um "pai gentil" que se vincula, tradicionalmente, à imagem de um "bom monarca” (PHILIPPIDES, 1984, p. 295-297). No Breviário (VIII, 16-18), Eutrópio é lembrado de forma respeitosa e um imperador morto por conspirações; Gordiano é louvado pelas suas campanhas militares, morto pelo traidor Filipe, O Árabe, e divinizado e honrado como deus (IX, 23); e Constâncio Cloro, particularmente, é alvo de um louvores significativos sobre o seu caráter:

\begin{abstract}
Ele era um homem notável e excepcionalmente gracioso, que demonstrou preocupação com a riqueza de provinciais e particulares em vez de perseguir meramente os interesses do tesouro, e disse que era melhor que os recursos do estado fossem mantidos por indivíduos do que serem mantidos em um único cofre, mas seu estilo de vida era tão modesto que, se nos feriados, ele precisasse fazer um banquete para um bom número de amigos, suas salas de jantar estavam dispostas com o talheres de particulares que ele havia pego de empréstimo, indo casa de casa em casa (Eutropius, Breviarium, X, 1).
\end{abstract}

Desse modo, nos parece muito mais lógico o busto de Antioquia ser, de fato, uma representação de Gordiano III, e pela história e trajetória deste imperador que estão eivadas por uma memória constituída de honrarias, que consideramos plausível também o envolvimento dessa imagem, junto com a dos outros dois imperadores, em práticas religiosas no âmbito do doméstico e do privado na Vila da Caserna.

\title{
Considerações finais
}

Nas palavras iniciais da conclusão de Derickesen Brinkerhoff (1970, p. 63), o autor afirma que os donos dessa coleção de esculturas eram, inicialmente, pagãos tendo se convertido ao cristianismo posteriormente e, portanto, as esculturas estão dentro de um contexto cultural pagão e depois cristão. De uma maneira ou de outra, o autor 
deixa implícito uma interpretação que avalia esses objetos como sendo mobiliários ornamentais com sentido educacional em espaço doméstico. Em nossa opinião, essa conclusão explica apenas parte da seleção e possessão dessa coleção de esculturas em contexto doméstico. Antioquia como uma metrópole composta por múltiplas comunidades religiosas, sincrética e fluída, também fazia reuso de estatuária e compartilhamentos de símbolos e uma paideia comum o que podia expressar ambiguidades, como podemos depreender, por exemplo, do caso de Constâncio Cloro e sua associação com divindades solares que podiam também serem identificados a imagem de Jesus, o deus cristão. As ambiguidades eram por vezes aceitas e, por vezes, rejeitadas. Assim, supomos que em um contexto inteiramente politeísta, os cristãos também poderiam diante de esculturas particulares e pagãs expressarem culto ou honra sob seu ponto de vista fazendo com que a vila de Antioquia fosse também palco de alianças e fidelidades religiosas entre os membros de uma elite mesmo que fossem eles adeptos do cristianismo ou do paganismo.

Sobre o culto imperial, em particular, não me parece haver uma oposição estrita entre cristãos e pagãos. Havia sim a possibilidade de uma convergência religiosacultural em relação à pessoa do imperador e culto. Assim, para concluir, o que essa coleção de Antioquia, nos convida a conhecer e refletir, é o tema da estatuária no espaço da vila, não somente como arte, objetos decorativos e ornamentais de um espaço, mas, como imagens, potencialmente, alvos de culto, reverência e defesa de uma ordem de mundo no qual imperadores e divindades ainda são vívidas aos olhos daqueles que as possuem bem como sob a perspectiva daqueles que, em visita as villae, se deparam com representações significativas no contexto da cidade de Antioquia entre os séculos IV e V d.C., uma metrópole cujas comunidades religiosas são heterogêneas, fluídas e que compartilham valores. A própria constituição material da vila romana antioquena é, portanto, um exercício de reflexão também à luz do âmbito do religioso e não somente como peças de uma ornamentação artística e dessacralizada. Em especial sobre o tema do culto imperial doméstico que nos últimos anos têm trazido à luz uma história fascinante no âmbito do contexto doméstico e privado.

\section{Referências}

BARNES, Timothy David. The Persian sack of Antioch in 253. Zeitschrift für Papyrologie und Epigraphik, Bd. 169, p. 294-296, 2009.

BLAND, Roger. From Gordian III to the Gallic Empire (238274). In: METCALF, W. E. The Oxford Handbook of Greek and Roman Coinage. Oxford: Oxford University Press, 2012, p. 514-537.

BOWES, Kimberly. At home. In: RAJA, R.; RÜPKE, J. A Companion to the Archaeology of Religion in the Ancient World. Oxford: WilleyBlackwell, 2015, p. 209-219.

BRINKERHOFF, Dericksen Morgan. A collection of sculpture in classical and early christian Antioch. New York: New York University Press, 1970. 
BURTON, Henry Fairfield. The Worship of the Roman Emperors. The Biblical World, v. 40, n. 2 , p. 80-91, 1912.

CALANDRA, Elena. Nota sul ritratto di Gordiano III al Palazzo Ducale di Mantova. Latomus, T. 48, Fasc. 4, p. 854-856, 1989.

CALLAHAN, Brahm. Living off the dead: the relationship between emperor cult and the cult of the saints in late antiquity. 2008. 66f. Dissertação (Mestrado em História) - Programa de Pós-Graduação em Artes e Ciência, The Graduate School of Art and Science, Boston College, Boston, 2008.

CAMPBELL, William Alexander. The Third Season of Excavation at Antioch-on-theOrontes. American Journal of Archaeology, v. 40, n. 1, p. 110, 1936.

CARVALHO, Margarida Maria de; SILVA, Erica Cristhyane Morais da. Os espetáculos e os teatros cobertos da Antiguidade Tardia: O caso do bouleuterion de Antioquia de Orontes (século IV d. C.). In: REVILLA CALVO, Victor; AGUILERA MARTíN, Antonio; PONS PUJOL, Lluís; GARCÍA SÁNCHEZ, Manel (ed.). Ex Baetica Romam. Homenaje a José Remesal Rodríguez. Barcelona: Universitat de Barcelona, 2020, p. 1353-1382.

CHARTIER, Roger. A história cultural. Rio de Janeiro: Bertrand Brasil, 1990.

DIGNAS, Beate; WINTER, Engelbert. Rome and Persia in Late Antiquity. Cambridge: Cambridge University Press, 2007.

DOBBINS, John. Houses at Antioch. In: KONDOLEON, Christine. Antioch: The lost city. Massachusetts: Princeton, 2000, p. 50-61.

DODGEON, Michael H.; LIEU, Samuel NanChiang. The roman eastern frontier and the persian wars AD 226-363. London: Routledge, 1991.

DOWNEY, Glanville. A history of Antioch in Syria: from Seleucus to the Arab Conquest. New Jersey: Princeton University Press, 1961.

DRINKWATER, John Frederick. Gordian III, Roman emperor. In: HORNBLOWER, Simon; SPAWFORTH, Antony; EIDINOW, Esther. Oxford Classical Dictionary. Oxford: Oxford University Press, 2016, p. 622.

DRINKWATER, John Frederick. Vibius Trebonianus Gallus, Gaius, Roman emperor Trebonianus Gallus. In: HORNBLOWER, Simon; SPAWFORTH, Antony; EIDINOW, Esther. Oxford Classical Dictionary. Oxford: Oxford University Press, 2016.

EICHHOLZ, D. E. Constantius Chlorus' Invasion of Britain. The Journal of Roman Studies, v. 43, p. 41-46, 1953.

ERIM, Kenan; REYNOLDS, Joyce. A Letter of Gordian III from Aphrodisias in Caria. Journal of Roman Studies, n. 59, p. 56-58, 1969.

FISHWICK, Duncan. Votive Offerings to the Emperor? Zeitschrift für Papyrologie und Epigraphik, Bd. 80, p. 121-130, 1990. 
GARZON BLANCO, José Antonio. El emperador Publio Helvio Pertinax em las fuentes. Estado de la cuestion. Baetica. Estudios de Arte, Geografia e Historia, n. 7, p. 195210, 1984.

GUEY, Julien. Les Res Gestae divi Saporis. Revue des Études Anciennes, v. 57, n. 12, p. 113-122, 1955.

GONÇALVES, Ana Teresa. Septímio Severo e a Consecratio de Pertinax: Rituais de morte e poder. História, v. 26, n. 1, p. 20-35, 2007.

GRAF, David F. Town and countryside in Roman Arabia during Late Antiquity. In: BURNS, Thomas S.; EADIE, John W. Urban centers and rural contexts in Late Antiquity. Michigan: Michigan State University Press, 2001, p. 219-240.

HARL, Kenneth W. Gordian III (Marcus Antonius Gordianus Augustus). In: BAGNALL, Roger S.; BRODERSEN, Kai; CHAMPION, Craige B. et al. The Encyclopedia of Ancient History. Oxford: WilleyBlackwell, 2013.

HARPER, Kyle. Pandemics and passages to late antiquity: rethinking the plague of c.249270 described by Cyprian. Journal of Roman Archaeology, v. 28, p. 223-260, 2015.

HEBBLEWHITE, Mark. The emperor and the army in the Later Roman Empire, AD 235-395. London: Routledge, 2016.

HERRMANN, Katrin. Gordian III: Kaiser einer Umbruchszeit. Speyer: KartoffeldruckVerlag, 2013.

HOLDER, Paul A. Legio II Parthica in Italy in the reigns of Gordian III and Philip. Liverpool Classical Monthly, v. 19, n. 9-10, p. 145-146, 1994.

HONIGMANN, Ernest; MARICQ, André. Recherches sur les Res Gestae Divi Saporis. Bruxelles: Palais des Academie, 1953.

HURLET, Frédéric. The roman emperor and the imperial family. In: BRUNN, Christer; EDMONDSON, Jonathan C. The Oxford Handbook of Roman Epigraphy. Oxford: Oxford University Press, 2015, p. 178-201.

INAN, Jale; ALFÖLDI-ROSENBAUM, Elisabeth. Römische und frühbyzantinische Porträtplastik aus der Türkei: neue Funde. Mainz, 127-130, n. 76, pls. 67.2 e 68, 1979.

JOHNSON, Mark J. The "Sepulcrum Gordiani" at Zaitha and Its Significance. Latomus, v. 54, n.1, p. 141-144, 1995.

JOHNSON, Mark J. Where were Constantius I and Helena Buried? Latomus, v. 51, n. 1, p. 145-150, 1992.

KETTENHOFEN, Erich. The Persian Campaign of Gordian III and the Inscription of Sahpuhr at the Ka'be-ye Zartost. In: MITCHELL, S (Ed.). Armies and Frontiers in Roman and Byzantine Anatolia. Oxford: British Archaeological Reports, 1983, p.151-171.

KESKIL, Suheyla. Hatay müzea rehberi. Istanbul: Ankara Universiteri Basimevi, 1964. 
KRIZINGER, Friedrich. et.al. Hanghaus 2 in Ephesos: Wohneinheiten 1 und 2; Baubefund, Ausstattung, Funde, Forschungen in Ephesos VIII.8. Wien: Verlag der Österreichischen Akademie der Wissenschaften, 2010.

LAIRD, Margaret L. Civic monuments and the Augustales in Roman Italy. Cambridge: Cambridge University Press, 2015.

LAIRD, Margaret L. Review: Emperor Worship and Roman Religion. Emperor worship and Roman religion. Oxford: Clarendon Press, 2002.

LENAGHAN, Julia. Discussion: Portrait bust of man in armour made from disparate elements. Antioch on the Orontes (Syria). Late third to early fourth century. Disponível em http://laststatues.classics.ox.ac.uk/database/discussion.php?id=626. Acesso em 28 maio 2020.

LEVI, Doro. Antioch mosaic paviments. Princeton: Princeton University Press, 1974.

LORIOT, Xavier. Les premières années de la grande crise du Ille siècle: De l'avènement de Maximin le Thrace (235) à la mort de Gordien III (244). Aufstieg und Niedergang der römischen Welt II, Band 2, p. 657-787, 1975.

MAcDONALD, David. The death of Gordian III: Another tradition. Historia: Zeitschrift für Alte Geschichte, Bd. 30, H. 4, p. 502-508, 1981.

MATTINGLY, Harold. The reigns of Trebonianis Gallus and Volusian and of Aemilian. The Numismatic Chronicle and Journal of the Royal Numismatic Society, v. 6, n. 1-2, p. 36-46, 1946.

MECKLER, M. L. Gordian III (238-244). In: De Imperatibus Romanis: An Online Encyclopedia of Roman Emperors. Disponível em https://www.roman-emperors.org/ gordo3.htm Acesso em 17 ago 2019.

MEIJER, Fik. Emperors Don't Die in Bed. London: Routledge, 2004.

MOORE, R. C. Trebonianus Gallus (251-253 A.D.) and Gaius Vibius Volusianus (251253 A.D.). In: De Imperatibus Romanis: An Online Encyclopedia of Roman Emperors. Disponível em http://www.roman-emperors.org/trebgall.htm Acesso em 17 ago 2019.

OLMSTEAD, A. T. The midThird century of the Christian Era. Classical Philology, v. 37, n. 3, p. 241-262, 1942.

OOST, Stewart Irving. The death of the emperor Gordian III. Classical Philology, n. 53, p, 106-107, 1958.

PETIT, P. Libanius et la vie municipale d'Antioche au IVe siècle après J.-C. Paris: P. Geuthner, 1955.

PHILIPPIDES, Marios. Herodian 2.4.1 and Pertinax. The Classical World, v. 77, n. 5, p. 295-297, 1984. 
POLLITT, Jerome Jordan. A Collection of Sculpture in Classical and Early Christian Antioch by Dericksen M. Brinkerhoff, a review. The Art Bulletin, v. 54, n. 2, p. 202203, 1972.

RATHMAYR, Elisabeth. Identity in the private sphere: interpreting houses as loci reflecting the identy of their inhabitants. In: MORTENSEN, Eva; POULSEN, Birte. Cityscapes and Monuments of Western Asia Minor: Memories and Identities. Oxford: Oxbow Books, 2017, p. 109-121.

RATHMAYR, Elisabeth. New Evidence for Imperial Cult in Unit 7 in Terrace House 2 in Ephesos. In: BLACK, A.; THOMAS, C. M.; THOMPSON, T. W. Ephesus as a religious center under the Principate. Tübingen: Mohr Siebeck, 2020.

RATHMAYR, Elisabeth. Gotter- und Kaiserkult im privaten Wohnbereich anhand von Skulpturen aus dem Hanghaus 2 in Ephesos. Römische historische Mitteilungen, v. 48, p. 103-135, 2006.

REA, John R. Gordian III or Gordian I? Zeitschrift für Papyrologie und Epigraphik, Bd. 76, p. 103-106, 1989.

RETIEF, François Pieter; CILLIERS, Louise. Causes of death among the Caesars (27 BCAD476). Acta Theologica Suplemmentum 7, v. 26, n. 2, p. 89-106, 2006.

ROBIN, Règine. La memoire saturée. Paris: Stock France, 2003.

ROSTOVTZEFF, Michael I. Res Gestae Divi Saporis and Dura. Berytus, n. 8, p. 17-60, 1943.

RUBIN, Zeev. The Roman Empire in the Res Gestae Divi Saporis. In: DABROWA, Edward. Ancient Iran and the Mediterranean World. Kraków: Jagiellonian University Press, 1998, p. 177-185.

SARTRE, Maurice. Le dies imperii de Gordien III: une inscription inédite de Syrie. Syria, n. 61, p. 49-61, 1984.

SCHÖRNER, Günther. Location of Domestic Rituals in the Roman Empire: An Interprovincial Comparison. Archiv für Religionsgeschichte, v. 1819, n. 1, p. 25-36, 2017.

SETTON, Kenneth M. Christian attitudes toward the emperor in the fourth century, especially as shown in adresses to the emperor. New York: Columbia University Press, 1941.

SILVA, Erica Cristhyane Morais da. O Platô de Dafne na Antiguidade Tardia: os usos do espaço e a relação com a asty de Antioquia de Orontes. In: LIMA NETO, Belchior Monteiro; SILVA, Erica Cristhyane Morais da; SILVA, Gilvan Ventura da. Formas e imagens da cidade antiga. Vitória: Milfontes, 2020, p. 201-230.

SMITH, Mark D. The religion of Constantius I. Greek, Roman and Byzantine Studies, n. 38, p. 187-209, 1997a.

SMITH, Mark D. The religious coinage of Constantius I. Bizantion, t. LXX, fasc. 2, p. 474-490, 2000. 
SMITH, R. R. R. The Public Image of Licinius I: Portrait Sculpture and Imperial Ideology in the Early Fourth Century. The Journal of Roman Studies, v. 87, p. 170-202 1997b.

STERN, Gaius. Trebonianus Gallus (Gaius Vibius Trebonianus Gallus Augustus). In: BAGNALL, Roger S.; BRODERSEN, Kai; CHAMPION, Craige B. et al. In: The Encyclopedia of Ancient History. Oxford: Willey Blackwell, 2012.

STILLWELL, Richard. Houses of Antioch. Dumbarton Oaks Papers, v. 15, p. 45-47-57, 1961.

STOLTE, B. H. The death of the emperor Gordian III and the reliability of the Res Gestae Divi Saporis. In: Acta of the Fifth International Congress of Greek and Latin Epigraphy, Cambridge, [18th to 23rd September], 1967. Oxford: Blackwell, 1971.

TANNER, Jeremy. Portraits, power, and patronage in the late roman republic. The Journal of Roman Studies v. 90, p. 18-50, 2000.

TAYLOR, Lily Ross. The divinity of the roman emperor. Philadelphia: Porcupine Press, 1975.

TOWNSEND, Prescott. Winson. The administration of Gordian III. Yale Classical Studies, v. 4, p. 59-132, 1934.

THÜR, Hilke et al. Hanghaus 2 in Ephesos: die Wohneinheit 4; Baubefund, Ausstattung, Funde, Forschungen in Ephesos 8.6. Wien: Verlag der österreichischen Akademie der Wissenschaften, 2005.

YANDEK, Amy C. Pagan roman religious acculturation? An inquiry into the domestic cult at Karanis, Ephesos, and Dura-Europos: The First to Fifth Centuries CE. 2013. 309f. Tese (Doutorado em História da Arte) - Programa de PósGraduação em História da Arte, Temple University Graduate School, Pennsylvania, 2013.

ZIMMERMANN, Norbert. Archaeological Evidence for Private Worship and Domestic Religion in Terrace House 2 at Ephesos. In: SCHOWALTER, Daniel; LADSTÄTTER, Sabine; FRIESEN, Steven J.; THOMAS, Christine. Religion in Ephesos Reconsidered. Leiden: Brill, 2019, p. 211-229.

\section{Documentação estatuária}

ARCHAEOLOGICAL ARCHIVES. 25H. Princeton University. Disponível em http://vrc. princeton.edu/archives/items/browse?tags=Barracks Acesso em 7 jul 2017.

LSA254. Portrait bust of man in armour made from disparate elements. Antioch on the Orontes (Syria). Late third to early fourth century. The Last Statues of Late Antiquity Database. Disponível em http://laststatues.classics.ox.ac.uk/database/detail. php?record=LSA-254 Acesso em 28 maio 2020.

LSA523. Porphyry head of Tetrarch (lost). From Antioch on the Orontes (Syria). Late third to early fourth century. The Last Statues of Late Antiquity Database. Disponivel em http://laststatues.classics.ox.ac.uk/database/detail.php?record=LSA-523 Acesso em 28 maio 2020. 


\section{Documentação arqueológica}

LEVI, Doro. Antioch mosaic pavements. Princeton: Princeton University Press, 1974.

STILLWELL, Richard. Antioch-on-the-Orontes II: The excavations of 19331936. Princeton: Princeton University Press, 1938, p. 215.

\section{Documentação escrita}

EUTROPIUS. Breviarium ab urbe condita. In: BIRD, H. W. The Breviarium ab Urbe Condita of Eutropius: The Right Honourable Secretary of State for General Petitions Dedicated to Lord Valens Gothicus Maximus \& Perpetual Emperor. Liverpool: Liverpool University Press, 2011.

ORACULA SIBYLLINA. In: OLMSTEAD, A. T. The midThird century of the Christian Era. Classical Philology, v. 37, n. 3, p. 241-262, jul., 1942.

RES GESTAE DIVI SAPORIS. In: MARICQ, A. Classica et Orientalia: 5. Res Gestae Divi Saporis. Syria, v. 35, n. 3/4, p. 295-360, 1958.

THEODOSIAN CODE. In: PHARR, C. Theodosian Code and Novels and the Sirmondian Constitutions. New Jersey: The Lawbook Exchange, 2001.

\section{Notas}

${ }^{1}$ As imagens (fotografias da escavação) podem ser consultadas em: Archaeological Archives Princeton University (http://vrc.princeton.edu/archives/) referente a Coleção do Committee for the Excavation of Antioch-on-the-Orontes 1932-1939. A fotografia da coleção de estátuas, no local onde foram enterradas (in situ): http://vrc.princeton.edu/archives/items/show/13976. As imagens imperiais: o busto referente à imagem de Pertinax, http://vrc.princeton.edu/archives/ items/show/14017 e http://vrc.princeton.edu/archives/items/show/14018. O busto de Antioquia descrito como "um imperador vestido com um corselete", imagem de Gordiano III: http://vrc. princeton.edu/archives/items/show/14019 e http://vrc.princeton.edu/archives/items/show/14020. A representação de Constâncio Cloro em cabeça porfiróide: http://vrc.princeton.edu/archives/ items/show/14023 e http://vrc.princeton.edu/archives/items/show/14024. Embora o escopo desse artigo não inclua o estudo acerca da estatuária referente as representações de deuses, heróis e personagens mitológicas que faz parte do conjunto de estátuas encontradas na Vila da Caserna, a seguir, indicamos as páginas do Archaeological Archives Princeton University, onde as imagens estão disponíveis e podem ser acessadas: http://vrc.princeton.edu/archives/ items/show/14034; http://vrc.princeton.edu/archives/items/show/14035; http://vrc.princeton. edu/archives/items/show/14021; http://vrc.princeton.edu/archives/items/show/14022; http://vrc. princeton.edu/archives/items/show/14039; http://vrc.princeton.edu/archives/items/show/14038; http://vrc.princeton.edu/archives/items/show/14025; http://vrc.princeton.edu/archives/items/ show/14026; http://vrc.princeton.edu/archives/items/show/14015; http://vrc.princeton.edu/archives/ items/show/14016; http://vrc.princeton.edu/archives/items/show/14033; http://vrc.princeton.edu/ archives/items/show/14030.

${ }^{2}$ Sobre o motivo das estátuas terem sido encontradas enterradas não temos uma resposta definitiva e final, mas explicações com respostas fragmentárias. Brinkerhoff (1970, p. 4) nos informa que há uma hipótese geral que postula a sobrevivência desta coleção na vila no século $\checkmark$ já que dificilmente poderia ser enterrada em uma sala até que ela fosse construída. Segundo 
essa hipótese, possivelmente, a coleção foi trazida de outro lugar e descartada depois que a residência foi abandonada, provavelmente durante o lento declínio de Antioquia, do segundo terço do século VI até a época da conquista árabe, no século VII. Brinkerhoff, no entanto, refuta essa hipótese afirmando que se estas estátuas tivessem vindo de outro lugar para serem descartadas, o mais lógico seria que o descarte tivesse acontecido num sítio mais próximo ao da localização original das estátuas. Para esse autor, ao contrário do que postula aquela hipótese, o local onde foi encontrada a coleção é, provavelmente, o indicativo de que essas peças adornavam o lugar onde foram encontradas. Para Brinkerhoff (1970, p. 68-72), o enterramento da coleção pode estar relacionado, grosso modo, às destruições produzidas em razão dos conflitos religiosos da época. Segundo este autor, a coleção de esculturas enterradas em Antioquia "sobreviveu ao fanatismo cristão em lugar recluso, provavelmente, como adornos da vila, continuando a ser peças decorativas, tendência da moda, até meados do século VI para os proprietários que eram, primeiro, pagãos e, depois, convertidos ao cristianismo, tendo a coleção não mais sobrevivido, acima do solo, após o saque persa, em Antioquia e seu subúrbio, em 540, que se torna uma data alternativa final para aquela mais tardia da conquista árabe para o enterramento da coleção", embora, "o vandalismo árabe, em 637, se torna uma data mais provável para a destruição e enterramento" das estátuas da coleção de Antioquia (BRINKERHOFF, 1970, p. 71-72).

\begin{abstract}
${ }^{3}$ Recorremos aqui ao conceito de memória como concebido por Régine Robin (2003, p. 27): "O passado não é livre. Nenhuma sociedade o deixa à própria sorte. Ele é regido, gerido, conservado, explicado, narrado, comemorado ou odiado. Seja celebrado ou ocultado, ele é um investimento fundamental do presente. Por causa desse passado frequentemente distante, mais ou menos imaginado, estamos prontos para lutar, estripar os vizinhos em nome da antiguidade de seus antepassados. Advém uma nova conjuntura, um novo horizonte de expectativas, a necessidade de novas bases, e nós o descartamos, esquecemos, colocamos à frente outros episódios, reencontramos, reescrevemos a história, inventamos antigas lendas em função de exigências do momento".
\end{abstract}

${ }^{4}$ INAN, J.; ALFÖLDI-ROSENBAUM (1979, p. 127-130) também argumenta em favor de uma representação de Treboniano Galo.

${ }^{5}$ Pertinax, Heliogábalo, Maximino, Maioriano, Antêmio foram decapitados (RETIEF; CILLIERS, 2006, p. 99).

${ }^{6}$ Há uma extensa bibliografia sobre a documentação epigráfica, vide: J. Guey (1955, p. 113-122); M. Rostovtzeff (1943, p. 17-60); E. Honigmann e A. Maricq (1953); E. Kettenhofen (1983); D. Macdonald (1981); S. I. OOST (1958); Z. Rubin (1998, p. 177-185); B. H, Stolte (1971).

${ }^{7}$ Os relatos sobre o sepulcro podem ser encontrados em Amm. Marc. XXIII, 5, 7, e 17; Epit. de caes. 27, 3; Eutropius. IX, 2, 3; Euseb. - Hieron., Chron., a. Abr. 2257 -60 (ed. Helm, 217); Festus 22; Zosimus III, 14; H. A. III Gord. 34, 2-3 (JONHSON, 1995, p. 141).

${ }^{8}$ Gordiano era um imperadorinfante, reina aos 13 anos em conjunto com a "regência" de Timesiteu, prefeito do pretório e de origem oriental. "No final dos anos 240 ou início de 241, Gordiano III indicou Timesiteo como prefeito do pretório. Timesiteo, que era de origem oriental, tinha uma longa carreira na adminsitração imperial como procurador em províncias que iam da Arábia à Gália e da Ásia à Alemanha. As habilidades comprovadas de Timesiteo rapidamente o tornaram a figura central no governo de Gordiano III, e a autoridade do prefeito do pretório foi reforçada pelo casamento de sua filha, Furia Sabinia Tranquillina, com o jovem imperador no verão de 241" (MECKLER, 2019, p. 1).

${ }^{9}$ Conhecemos mais a face "pública" do culto imperial muito, em parte, devido à extensa historiografia sobre o tema que privilegiou o culto imperial "público" e, em parte, em razão das raras evidências disponíveis sobre o contexto doméstico e privado que implicou num 
desenvolvimento e avanços dos instrumentais teóricometodológicos disponíveis para que nos fossem permitido interpretar os documentos e as evidências com rigor. Como "público", talvez, equivocadamente, leiase tarefa do estado imperial e relacionado à coletividade combinado a ocorrência dos cultos em espaço da urbs/asty excetuando o espaço doméstico e residenciais. Essa compreensão gera, no entanto, problemas por opor o público ao privado. Para uma melhor compreensão e detalhamento sobre os conceitos de "público", "privado" e "doméstico" concernentes ao culto imperial, vide nota 10.

${ }^{10}$ Há um equívoco em pensar numa oposição binária entre público e privado de modo a considerar o espaço "doméstico" como sinônimo de "privado" e o espaço urbano (das ruas e dos edifícios de burocracia imperial) como o espaço das atividades "publicas". Como destaca Kimberly Bowes (2015, p. 209), a religião antiga doméstica como uma religião "privada" apresenta problemas já que as residências antigas não eram privadas na medida em que eram "permeáveis a todos os tipos de pessoas não pertencentes aos familiares (residentes) enquanto, por outro lado, a religião "pública" do templo, sinagoga e igreja afetava as práticas domésticas de maneiras complexas". De fato, as práticas rituais com base doméstica "abrangia comunidades que se estendiam muito além da família nuclear; referenciavase e, frequentemente, imitava rituais realizados em fóruns comunitários; e, em alguns períodos, situava-se em espaços projetado para fazer parte de um aparato de status externo da casa que era, pelas definições modernas, bastante público" (BOWES, 2015 , p. 209). Sobre o conceito de "privado", como argumenta Margaret L. Laird (2015, p. 85, vide nota 28), compreendemos que o termo 'privado' reflete o uso do espaço por um determinado e restrito grupo e não por sua localização em uma residência ou no espaço doméstico. Günther Schörner (2017, p. 25-26) argumenta que, no "direito romano, há uma distinção clara entre sacra publica e sacra privata" e, conforme "Festo, que escreveu no século II d.C., os rituais públicos (sacra publica) eram aqueles que eram realizados com custos públicos em nome de todo o povo, em contraste com os rituais privados [privata] que eram realizados em nome de pessoas, famílias ou famílias. Assim, a publicidade depende do financiamento, deixando toda atividade religiosa fora desse limite para o domínio dos cultos privados. Portanto, sacra privata incluía, é claro, todos os cultos realizados em uma casa ou moradia porque o dominus pagava por tudo. Mas os ritos privados não se limitam a esses rituais domésticos, porque todos os cultos fora das casas que não obtiveram reconhecimento e financiamento oficiais do Estado eram considerados privados também. Segundo Festo, todos os rituais realizados por associações religiosas ou outras eram "religião particular". É claro que essa definição jurídica de Festo não é o que entendem os observadores modernos porque a religião privada, no sentido moderno, é entendida principalmente como o oposto do culto do estado - outro termo problemático - e por isso sinônimo de "religião individual" ou "religião pessoal", às vezes com subtexto de um protestantismo histórico. Portanto, o termo "religião privada”, na opinião de Schörner, deverá ser abandonado em favor de uma categoria mais neutra, com foco no cenário local das atividades religiosas na casa. Nesse sentido, para o autor, o conceito de "rituais domésticos" parece ser mais apropriado. Logo, optaremos aqui pelo uso do termo "rituais doméstico" e espaço "doméstico" para designar as práticas religiosas no âmbito da Vila da Caserna, espaço de nossa consideração no presente artigo, e que incorpora tanto o "público" quanto o "privado"."

${ }^{11}$ Os problemas e as dificuldades de interpretação dos artefatos arqueológicos resultantes das campanhas de escavação de residências, em Antioquia, referemse tanto às motivações dos arqueólogos que direcionaram as campanhas em prol da recuperação de mosaicos e pouco ainda se fez acerca da estatuária bem como acerca das configurações arquitetônicas. Ao contrário de Éfeso, em Antioquia, pouco sobreviveu paredes das residências em razão das pilhagens (STILLWELL, 1961, p. 46-57; DOBBINS, 2000, p. 50-61). 
${ }^{12}$ Brinkerhoff (1970, p. 14) nos alerta que a cabeça e o torso (com a couraça) não são uma combinação perfeita e que há um corte entre a cabeça e o torso de modo que a cabeça tenha sido uma substituição da cabeça original e que, de fato, essa prática de reuso encontra respaldo em Jerônimo que afirma que “...quando um tirano é morto, suas estátuas e imagens são derrubadas, as cabeças destas removidas e substituídas pela cabeça do rival vitorioso, por ser removido novamente por sua vez, enquanto os corpos [das estátuas] permanecem intocados".

Érica Cristhyane Morais da SILVA. Doutora em História, é professora do Departamento de História da Universidade Federal do Espírito Santo, Vitória-ES, Campus de Goiabeiras. Pesquisadora do Laboratório de Estudos sobre o Império Romano, Seção do Espírito Santo (LEIR-ES) e do Grupo do Laboratório de Estudos sobre o Império Romano, Seção de Franca, São Paulo (G.LEIR - Franca/ SP). Dentre suas publicações destacam-se a organização dos livros Formas e imagens da cidade antiga (Vitória: Milfontes, 2020) em conjunto com Gilvan Ventura da Silva e Belchior Monteiro Lima Neto e História Militar do Mundo Antigo (São Paulo: Annablume, 2012) em conjunto com Pedro Paulo Abreu Funari, Margarida Maria de Carvalho e Cláudio Umpierre Carlan.

\section{Editores}

Paulo Cesar Gonçalves e Valéria dos Santos Guimarães
Submissão: 30/05/2020

Aceite: $23 / 07 / 2020$ 